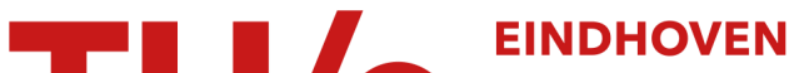 UNIVERSITY OF TECHNOLOGY
}

\section{Fluorescence emission and fluorescence quenching as detection methods in isotachophoresis}

Citation for published version (APA):

Reijenga, J. C., Verheggen, T. P. E. M., \& Everaerts, F. M. (1984). Fluorescence emission and fluorescence quenching as detection methods in isotachophoresis. Journal of Chromatography, 283(1), 99-111. https://doi.org/10.1016/S0021-9673(00)96245-9

DOI:

10.1016/S0021-9673(00)96245-9

Document status and date:

Published: 01/01/1984

\section{Document Version:}

Publisher's PDF, also known as Version of Record (includes final page, issue and volume numbers)

\section{Please check the document version of this publication:}

- A submitted manuscript is the version of the article upon submission and before peer-review. There can be important differences between the submitted version and the official published version of record. People interested in the research are advised to contact the author for the final version of the publication, or visit the $\mathrm{DOI}$ to the publisher's website.

- The final author version and the galley proof are versions of the publication after peer review.

- The final published version features the final layout of the paper including the volume, issue and page numbers.

Link to publication

\section{General rights}

Copyright and moral rights for the publications made accessible in the public portal are retained by the authors and/or other copyright owners and it is a condition of accessing publications that users recognise and abide by the legal requirements associated with these rights.

- Users may download and print one copy of any publication from the public portal for the purpose of private study or research.

- You may not further distribute the material or use it for any profit-making activity or commercial gain

- You may freely distribute the URL identifying the publication in the public portal.

If the publication is distributed under the terms of Article 25fa of the Dutch Copyright Act, indicated by the "Taverne" license above, please follow below link for the End User Agreement:

www.tue.nl/taverne

Take down policy

If you believe that this document breaches copyright please contact us at:

openaccess@tue.nl

providing details and we will investigate your claim. 

TECTION METHODS IN ISOTACHOPHORESIS

\author{
J. C. REIJENGA*, Th.P.E.M. VERHEGGEN and F.M. EVERAERTS
}

Laboratory of Instrumental Analysis, University of Technology, P.O. Box 513, $5600 \mathrm{MB}$ Eindhoven (The Netherlands)

(Received August 25th, 1983)

\title{
SUMMARY
}

Equipment for simultaneous fluorescence and UV absorption detection in isotachophoresis is described and evaluated. The sensitivity and linearity of the method were determined with quinine and fluorescein as reference substances. The possible fields of application are illustrated with the isotachophoretic analysis with fluorescence detection of quinine in soft drink, the vitamin $B_{6}$ compounds pyridoxamine, pyridoxal and pyridoxine in a pharmaceutical dosage form and bovine serum albumin, and the analysis of an amino acid at neutral $\mathrm{pH}$ as a fluorescamine derivative. The use of fluorescence quenching as a method of identification for non-fluorescent compounds is illustrated in an operational system with quinine as a fluorescent counter ion. Strong and weak unidentified components can thus be distinguished.

\section{INTRODUCTION}

The performance of analytical separation techniques is improved when a more specific detection system can be applied. It makes the method less susceptible to interferences from the matrix in which the compounds of interest are to be determined, and also gives a greater sensitivity. In capillary isotachophoresis, the detection limit of the universal (a.c. conductivity/potential gradient) detector is determined by the detector cell volume ${ }^{1}$. The same applies to the UV detector, except when using the "spike" method $^{2}$. Dual-wavelength detection ${ }^{3}$ also gives greater specificity.

The detection unit developed for dual-wavelength UV absorption detection in isotachophoresis, in which two beams of light penetrate the sample zone perpendicular to each other, makes fluorescence detection in a cell volume of less than $10 \mathrm{nl}$ possible. Simultaneously, the absorption at the wavelength of excitation can be monitored.

\section{EXPERIMENTAL}

The isotachophoretic experiments were performed in equipment developed and built by Everaerts et al. ${ }^{1}$, with the following modifications. The light source was a 150 W xenon arc lamp used in conjunction with an excitation grating monochromator of a 
a

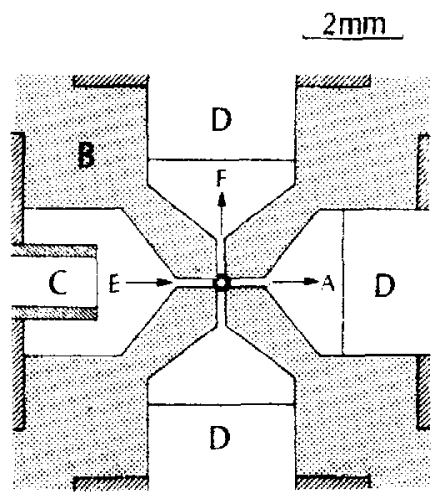

b

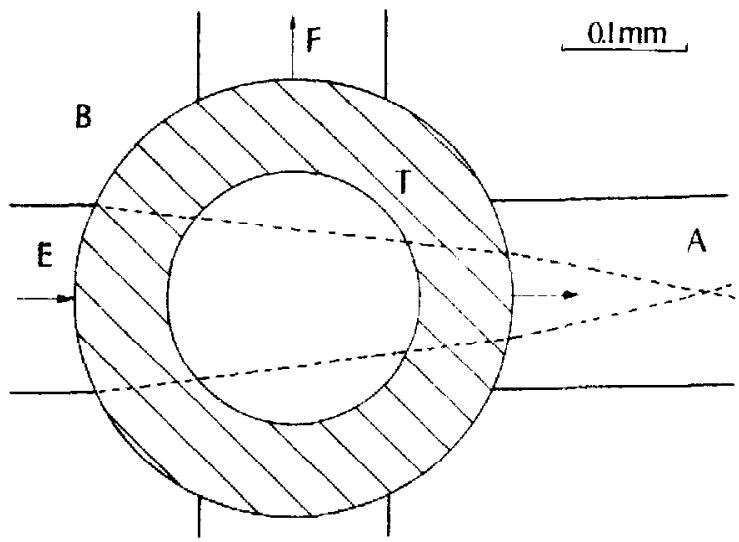

Fig. 1. Construction of the detection unit. The PTFE capillary (T) is mounted in a brass holder (B) into which four slits are drilled equiplanar. Light is conducted with a quartz optical fibre (C) or quartz rods (D). Perpendicular to the excitation (E), fluorescence emission (F) is measured. The absorption at the wavelength of excitation is monitored simultaneously (A).

Model MK-1 spectrofluorimeter (Farrand, New York, NY, U.S.A.). The grating caused some polarization of the incident light, which, after the excitation slit, was conducted to the detection unit with a $400-\mathrm{mm}$ quartz optical fibre of $1 \mathrm{~mm}$ diameter, allowing a spectral bandwidth of $10 \mathrm{~nm}$. Because of a radial refractive index gradient within this fibre, a parallel beam of light can be assumed to enter the detection unit.

Fig. 1a shows a cross-section of the detection unit for dual-wavelength UV absorption detection in isotachophoresis as introduced earlier ${ }^{3}$. The material used was brass. The PTFE capillary in which the analyses were carried out was pulled through a $0.35 \mathrm{~mm}$ hole in this unit, perpendicular to which, were drilled equiplanar four holes of $c a .0 .15 \mathrm{~m}$ diameter. The refractive index of PTFE (1.30-1.40) will cause the incident light to be focused (Fig. 1b). In the range $300-400 \mathrm{~nm}$ the $0.075 \mathrm{~mm}$ thick PTFE wall will absorb $c a .96 \%$ of the incident light. There is virtually no difference in refractive index between PTFE and water (1.33). As can be seen in Fig. 1b, the focusing of the light will give rise to a higher intensity at the next water-PTFE interfacc. This factor was calculated to be approximately 1.4 . Then again $c a .96 \%$ of the light is absorbed by the capillary wall and further focusing takes place outside the capillary in the brass slit. The loss of light due to dispersion in the exit slit is significant. After a path length of $c a .2 \mathrm{~mm}$ in air, a quartz rod of $3 \mathrm{~mm}$ diameter and $60 \mathrm{~mm}$ length mounted in a brass holder conducts the light towards a photodiode detector for absorption measurements. The detector was equipped with a UV-bandpass filter, Type CS 7-54 (Corning Glass,No. 9863) and a continuously variable neutral density filter consisting of two sheets of polarizing material. The latter was necessary to prevent detector overload. The fluorescence emission was measured perpendicular to the excitation. Owing to the random direction of the fluorescence emission, only ca. $5 \%$ will eventually reach the exit slit, even without taking into account the absorption by the PTFE wall. The exit slits for absorption and emission were identical, so that significant loss of emission intensity was also inevitable, especially due to dispersion. For emission measurement, the narrow- 
band filter normally used in UV absorption detection in isotachophoresis was replaced with a high-pass cut-off filter, Type CS 3-72 (Corning Glass No. 3387), unless otherwise indicated. The amplification of the current from the photodiodes was $10^{6}$. The detector signals were registered with a potentiometric recorder, Type BD 41 (Kipp, Delft, The Netherlands) and a PUZZLE microprocessor system (E. Steiner, Vienna, Austria) running a BASIC program described elsewhere ${ }^{3}$.

The operational systems for the isotachophoretic analyses were made from analytical-reagent grade chemicals purchased from either Merck (Darmstadt, G.F.R.) or Sigma (St. Louis, MO, U.S.A.).

\section{RESULTS AND DISCUSSION}

The detection unit was tested with quinine and fluorescein as model substances. The emission was measured with a 470-nm high-pass filter. The relationship between fluorescence intensity $(F)$ and concentration $(c)$ is

$$
F=\Phi_{F} I_{0}\left(1-\mathrm{e}^{-\varepsilon l c}\right)
$$

where $\Phi_{F}$ is the quantum yield, $I_{0}$ the intensity of the excitation, $\varepsilon$ the molar absorptivity at the wavelength of excitation and $l$ the path length. If for, e.g. dilute solutions, elc $<<1$, then eqn. 1 reduces to

$$
F=\Phi_{F} I_{0} \varepsilon l c
$$

The relative intensity of the light source $I_{0}$ was calculated with the aid of eqn. $1, \Phi_{F}$ values from literature ${ }^{4}$ and the fluorescence intensities $(F)$ of the reference solutions. It amounted to ca. $9 \cdot 10^{-12} \mathrm{~A}$ in the range $330-360 \mathrm{~nm}$ with a $10-\mathrm{nm}$ excitation bandwidth (see Table I).

A drawback of PTFE in optical detection systems in isotachophoresis is the loss of UV light. With a wall thickness of $0.075 \mathrm{~mm}$, the loss of UV light over the entire capillary amounted to $99.8 \%$ in the range $300-400 \mathrm{~nm}$. The use of quartz capillaries in this respect is under investigation. A higher signal level is especially important if the signal amplitude is used instead of zone length for quantitation. Although the measuring cell volume is less than $10 \mathrm{nl}$, with a path length of $0.2 \mathrm{~mm}$, the relatively high concentration of the sample ions in the steady state ( $c a .0 .01 M$ ) makes fluorescence detection in isotachophoresis possible.

UV absorption in capillary isotachophoresis is usually in the range $0.1-1$ absor-

TABLE I

EVALUATION OF FLUORESCENCE DETECTION SYSTEM FOR CAPILLARY ISOTACHOPHORESIS WITH STANDARD SOLUTIONS

See text for further explanation.

\begin{tabular}{lllllll}
\hline Substance & Solution & $\begin{array}{l}\text { Transmission } \\
(\%)\end{array}$ & $\Phi_{F}$ & $\begin{array}{l}F \\
(p A)\end{array}$ & $\begin{array}{l}\lambda_{\text {ex }} \\
(n n)\end{array}$ & $\begin{array}{l}I_{0} \\
(p A)\end{array}$ \\
\hline Quinine & $1 \mathrm{mM}$ in $1 \mathrm{~N} \mathrm{H}_{2} \mathrm{SO}_{4}$ & 15 & 0.51 & 2.5 & 360 & 8.7 \\
Fluorescein & $1 \mathrm{mM}$ in $0.1 \mathrm{~N} \mathrm{NaOH}^{2}$ & 21 & 0.9 & 4 & 330 & 9.0 \\
\hline
\end{tabular}


TABLE II

\section{OPERATIONAL SYSTEMS USED FOR THE ISOTACHOPHORETIC EXPERIMENTS}

PVA $=$ poly $($ vinyl alcohol $) ;$ HEC $=$ hydroxyethylcellulose; HEPES $=\mathrm{N}-2$-hydroxyethylpiperazine- $\mathrm{N}^{\prime}-2$-eth anesulphonic acid; $\mathrm{MES}=2$-(N-morpholino)ethanesulphonic acid; Tris $=$ tris(hydroxymethyl)aminomethane. The driving current was $25 \mu \mathrm{A}$ in a $0.2 \mathrm{~mm}$ I.D. capillary.

\begin{tabular}{llll}
\hline Parameter & $\begin{array}{l}\text { Standard } \\
\text { cationic }\end{array}$ & $\begin{array}{l}\text { Standard } \\
\text { anionic }\end{array}$ & $\begin{array}{l}\text { Fluorescent } \\
\text { anionic }\end{array}$ \\
\hline Leading ion & Potassium & Chloride & Chloride \\
Concentration & $0.01 M$ & $0.01 M$ & $0.01 M$ \\
Counter ion & Acetate & Histidine & Quinine \\
$\mathrm{pH}$ & 5.0 & 6.0 & 4.13 \\
Additive & None & $0.05 \%$ PVA & $0.2 \% \mathrm{HEC}$ \\
Terminating ion & $\mathrm{H}^{+}$ & HEPES & MES \\
Concentration & $c a .10^{-5} M$ & $c a .0 .005 M$ & $c a .0 .005 \mathrm{M}$ \\
Counter ion & Acetate & Tris & Tris \\
pH & $c a .5$ & $c a .7$ & $c a .7$ \\
\hline
\end{tabular}

bance unit, which means that the intensity of the fluorescence emission (eqn. 1) is no longer linearly related to the concentration (concentration quenching). This was verified experimentally by the isotachophoretic analysis of quinine and fluorescein in a cationic and an anionic operational system, respectively (Table II). The corresponding excitation spectra thus determined are shown in Fig. 2. The concentration of the sample

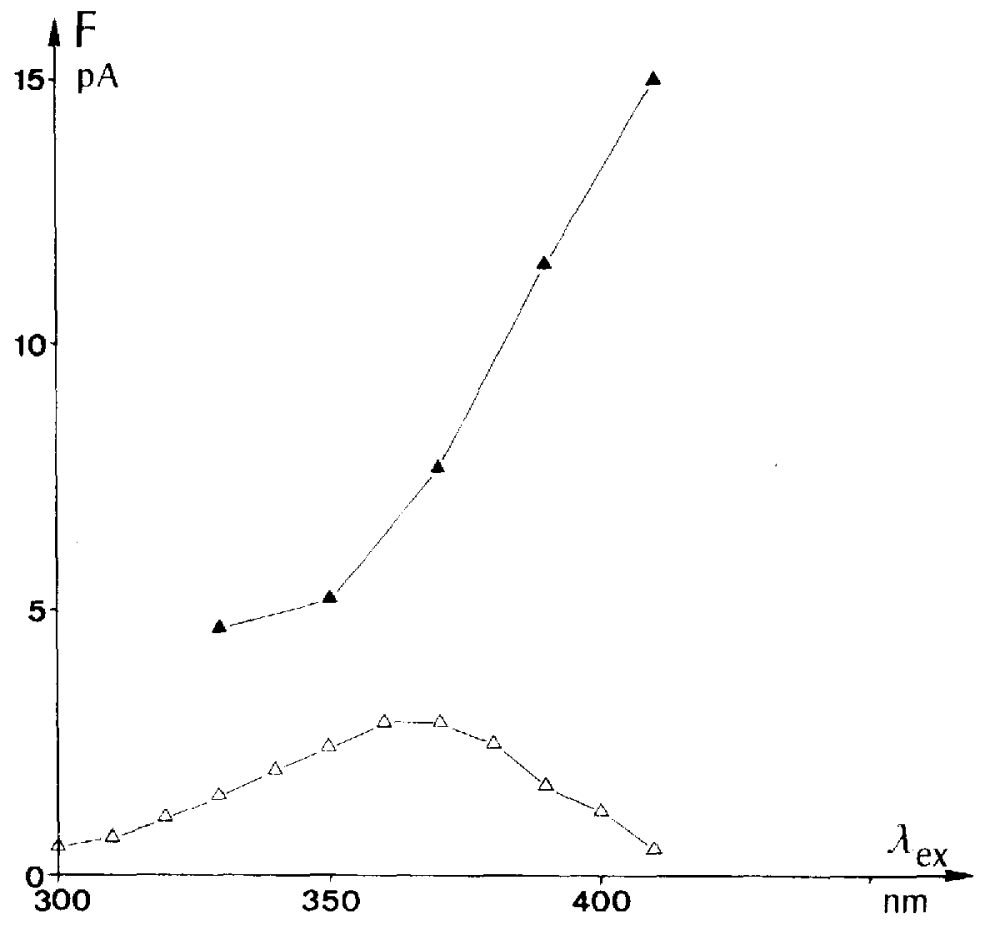

Fig. 2. Excitation spectra of fluorescein $(\boldsymbol{\Delta})$ and quinine $(\Delta)$ migrating isotachophoretically in an anionic and cationic operational system (Table II). 
a
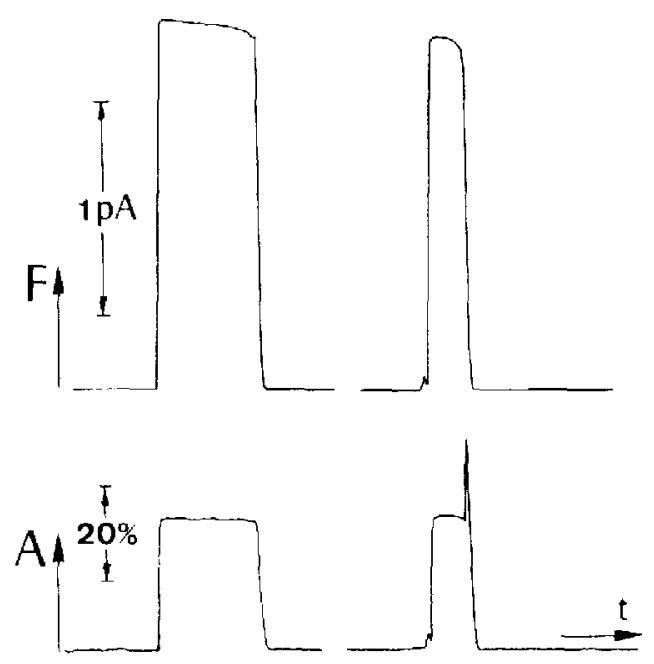

Fig. 3. Isotachophoretic analysis with simultaneous UV absorption (A) and fuorescence emission (F) detection of (a) a $400 \mathrm{ng}$ quinine standard and (b) a $5-\mu \mathrm{l}$ soft drink containing $30 \mathrm{mg} / \mathrm{l}$ of quinine. The wavelength of excitation was $370 \mathrm{~nm}$. For the cationic operational system, see Table II.

constituents in their zones are in the range $5-10 \mathrm{~m} M$, that is, 5-10 times as high as in the standard solution in Table I. The resulting fluorescence, however, is approximately the same for quinine (Fig. 3), which can be ascribed to quenching due to $\mathrm{pH}$, concentration, viscosity, the effect of the counter ion and the temperature profile in the capillary.

The temperature rise in the zones due to the heating effect of the driving current is small in a $0.2 \mathrm{~mm}$ I.D. capillary. We did not observe any influence of the driving current on the fluorescence intensity of quinine and fluorescein, although temperature is known to have a pronounced effect on fluorescencc intensity. The results have shown that although significant quenching may take place, fluorescence detection of zones in isotachophoresis is possible.

The relatively high signal-to-noise ratios $(\mathrm{S} / \mathrm{N})$ encountered will make the method even more useful for the detection of spikes, and eventually capillary zone electrophoresis ${ }^{5}$. Because of the serious dependence of fluorescence intensity on the conditions ( $\mathrm{pH}$, concentration, temperature, viscosity, impurities), a deviation from linearity with the spike method was expected, because of its susceptibility to interference from adjacent zones (spacers, impurities). A calibration graph for quinine at the sub-nanomole level was constructed (Fig. 4) using the heights of the fluorescence and absorption spikes. The absorption was sufficiently linear with respect to concentration at levels below $10 \%$ absorption, as expected. Fluorescence, however, did show nonlinearity, as illustrated by the fluorescence/absorption ratio (Hig. 4), which is a qualitative indication of quenching. However, it cannot be attributed solely to concentration quenching at detector cell absorption percentages in the range $0-20 \%$. The increase in the fluorescence of fluorescein was more evident (Fig. 2), especially in the range $350-400$ $\mathrm{nm}$ for the excitation. For this compound an emission filter with a cut-off wavelength 


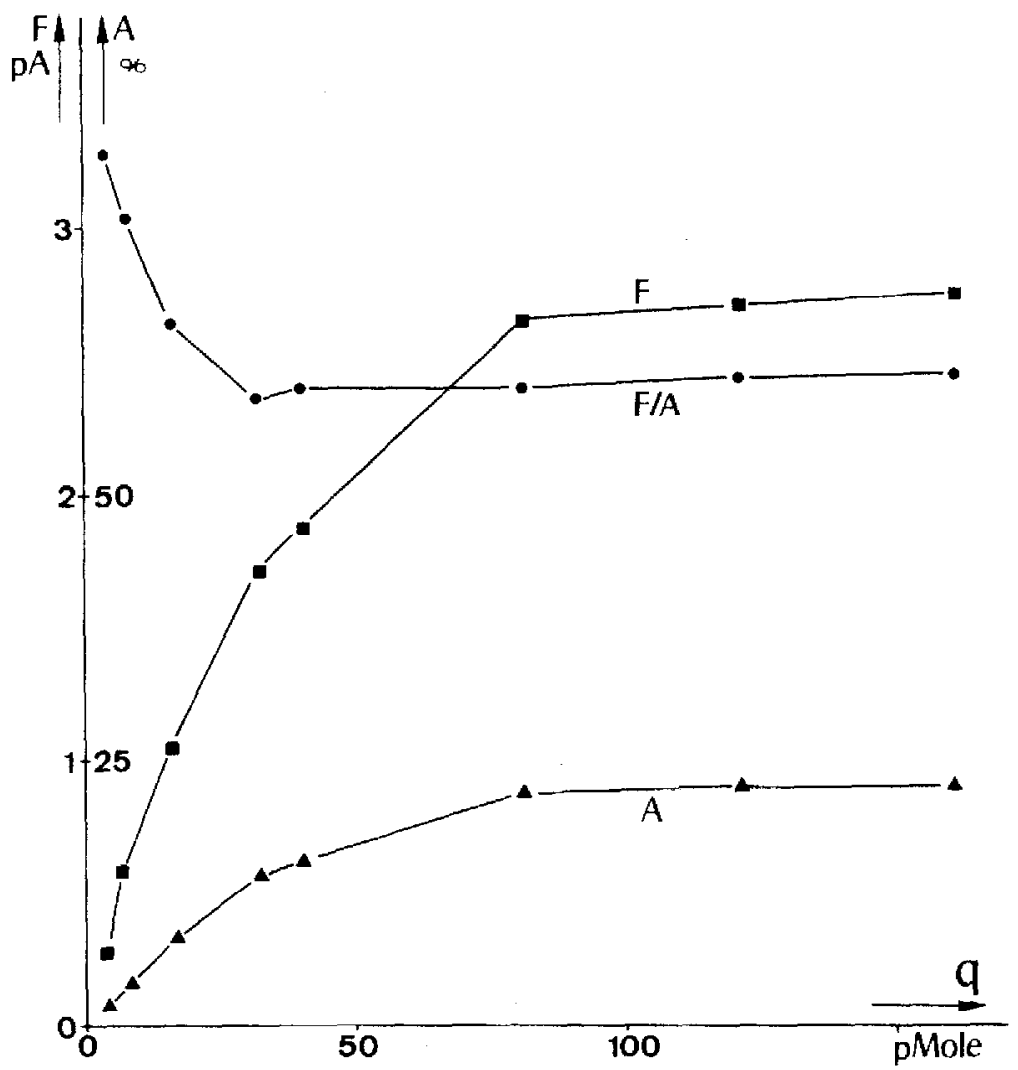

Fig. 4. Calibration graphs of quinine with the spike method in isotachophoresis. The absorption spike height (A) is linear below 25 pmole. The fluorescence height ( $\bullet$ ) remains non-linear because of quenching ( $\bullet$ ). Sce text for further explanation.

higher than $470 \mathrm{~nm}$ would have been more appropriate, although fluorescein could be detected with $S / N 30,000$ when excited at $410 \mathrm{~nm}$ in the present configuration. Quinine is detected with $S / N 600$, a value acceptablc in the detection of isotachophoretic zones.

An application of the determination of quinine with fluorescence detection is shown in Fig. 3. Both fluorescence and absorption traces are shown for the determination of quinine in soft drink. The UV absorption exibits an $S / N$ inferior to that of fluorescence. Part of the specificity of fluorescence detection is found in the possibility of optimizing both the excitation and emission wavelengths. In the equipment described, only the wavelength of excitation is tunable with a monochromator. For emission a choice is made from a number of high-pass cut-off filters. Because of the high bandwidth, this increases the sensitivity.

In the case of substances that show fluorescence in the range $350-450 \mathrm{~nm}$, an emission filter Type CS 0-52 (Corning Glass, No. 7380) can be used. An example is shown in Fig. 5 for the separation of vitamin $B_{6}$ constituents. The analysis was carried out in standard equipment ${ }^{1}$ for conductivity (Fig. 5a) and UV absorption detection (Fig. $5 b$ ) at $254 \mathrm{~nm}$. In a separate run, UV absorption at the wavelength of excitation (Fig. 
a

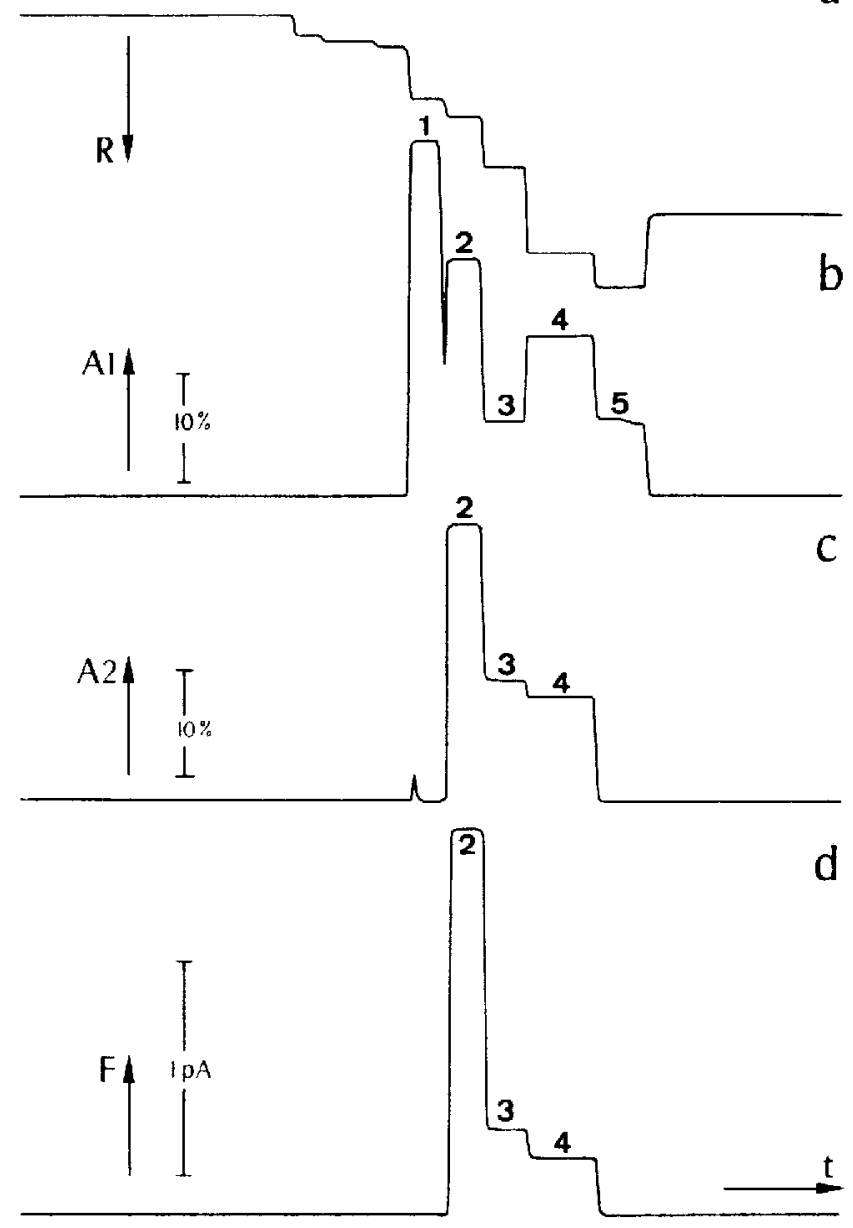

Fig. 5. Analysis of B-vitamin constituents in a cationic operational system (Table II) with conductivity detection (R), UV absorption at $254 \mathrm{~nm}$ (A1), UV-absorption at $340 \mathrm{~nm}$ (A2), the wavelength of excitation and fluorescence emission (F) with an emission filter, Type CS 0-52.1 = Thiamine $B_{1} ; 2=$ pyridoxamine $\mathbf{B}_{6} ; 3=$ pyridoxine $\mathrm{B}_{6} ; 4=$ pyridoxal $\mathbf{B}_{6} ; 5=$ icotinamide.

5c) and fluorescence emission (Fig. 5d) were measured. Pyridoxamine, pyridoxine and pyridoxal were detected specifically in a standard mixture. Excitation was at $340 \mathrm{~nm}$, the optimal wavelength in terms of response. The standard mixture also contained thiamine and nicotinamide which did not exhibit fluorescence. Computerized data reduction on the basis of the ratio of simultaneously detected fluorescence emission and UV absorption is possible. The computer program used was the same as for dual-wavelength UV absorption described elsewhere ${ }^{3}$.

An example is shown in Fig. 6, where from the absorption at the wavelength of excitation (Fig. 6a) and the fluorescence emission (Fig. 6b) the fluorescence/absorption ratio was calculated and plotted (Fig. 6c). Data reduction on the basis of this ratio yielded a fluorescence plot (Fig. 6d) of only those zones which comply with a certain 


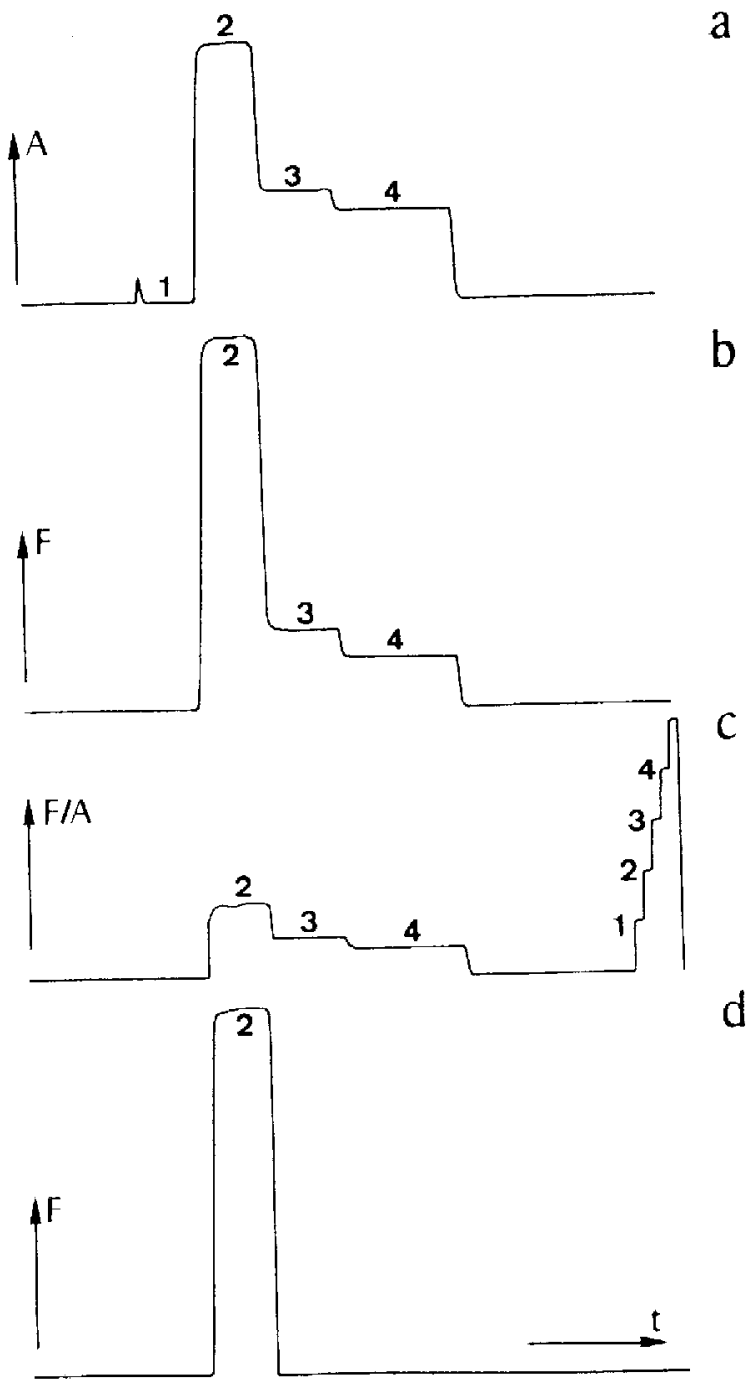

Fig. 6. Computerized data reduction of the analysis in Fig. 5. From the absorption (a) and fluorescence signals (b), the fluorescence/absorption ratio is calculated and plotted (c). In (d) only the zone with fluorescence/absorption ratio of $1.4 \pm 10 \%$ is selected.

ratio, in this instance 1.4 for pyridoxamine. The absorption and excitation spectra of the vitamin $\mathrm{B}_{6}$ compounds were constructed by repeated analysis at different wavelengths of excitation. These experiments have shown that although the optimal wavelength of excitation was in the range $340-350 \mathrm{~nm}$, the wavelength of maximum absorption was in the range $300-320 \mathrm{~nm}$. This is contrary to what is generally encountered ${ }^{4}$. Fig. 7 shows the fluorimetric determination of pyridoxine in a pharmaceutical dosage form (B-complex tablet) containing $0.75 \%$ of pyridoxine hydrochloride. The sample was dissolved and directly injected.

Proteins can be detected by their relatively weak native fluorescence, which is 

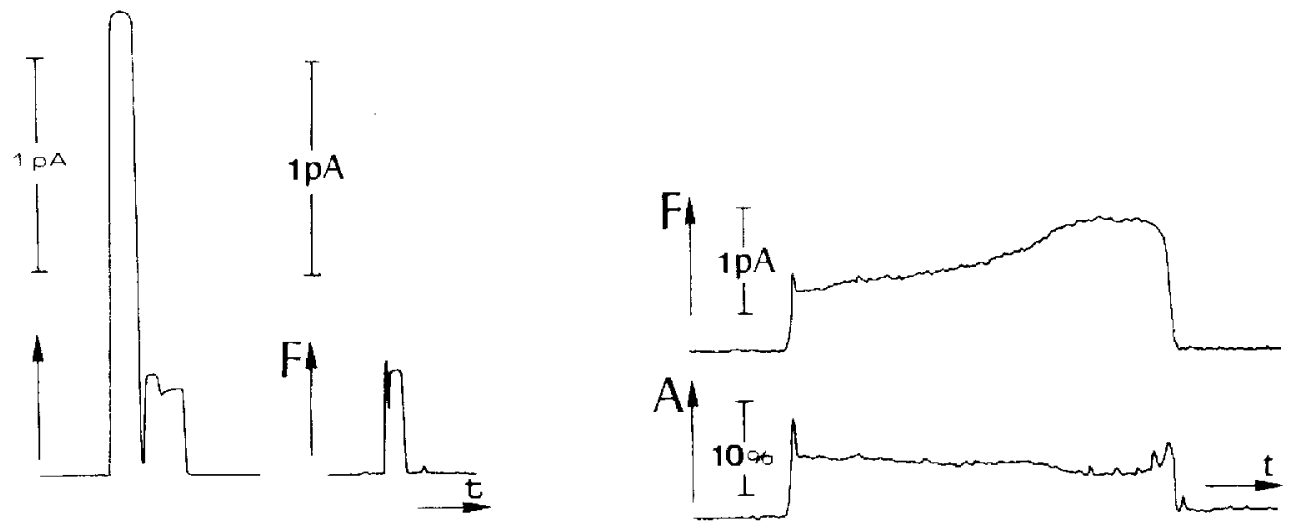

Fig. 7. Selective detection of $0.75 \%$ pyridoxine hydrochloride in a pharmaceutical dosage form of B vitamins. Conditions as in Fig. 5 and Table II.

Fig. 8. Isotachophoretic analysis of $33 \mu \mathrm{g}$ of bovine serum albumin as a cation (Table II), with UV absorption (A) and fluorescence detection (F) optimized for tryptophan. Wavelength of excitation, $300 \mathrm{~nm}$; emission filter, Type CS 0-52.

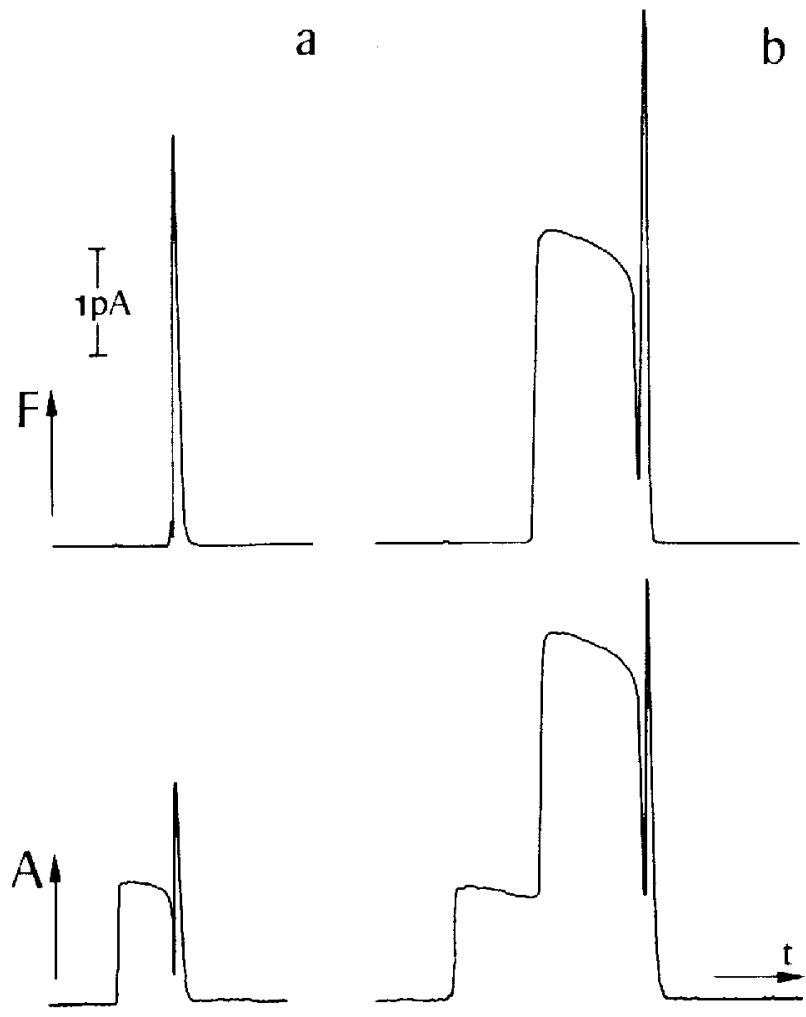

Fig. 9. Fluorescence detectiun of nuorescamine derivatives. A blank run (a) shows a non-fluorcsecnt reaction product. Excess of reagent did not interfere in the fluorescence detection of the $\alpha$-alanine derivative (b). Wavclength of excitation, $390 \mathrm{~nm}$; emission filter, Type CS 3-72. 
mainly due to amino acids such as tryptophan. Fig. 8 shows the analysis of bovine serum albumin (BSA) as detected by UV absorption and fluorescence. The optimal wavelength of excitation was $300 \mathrm{~nm}$, corresponding to the value reported for tryptophan. The fluorescence of an amino acid in a protein is known to depend on its environment, i.e., the protein conformation ${ }^{4}$. Conformational studies of proteins during their isotachophoresis can thus be performed with fluorescence detection.

For spectrofluorimetric determinations of proteins, a reaction with a fluorescent reagent is usually preferred. The interaction of human serum albumin (HSA) with one such fluorescent dye, 8-anilino-1-naphthalenesulphonic acid (ANS), was investigated ${ }^{6}$

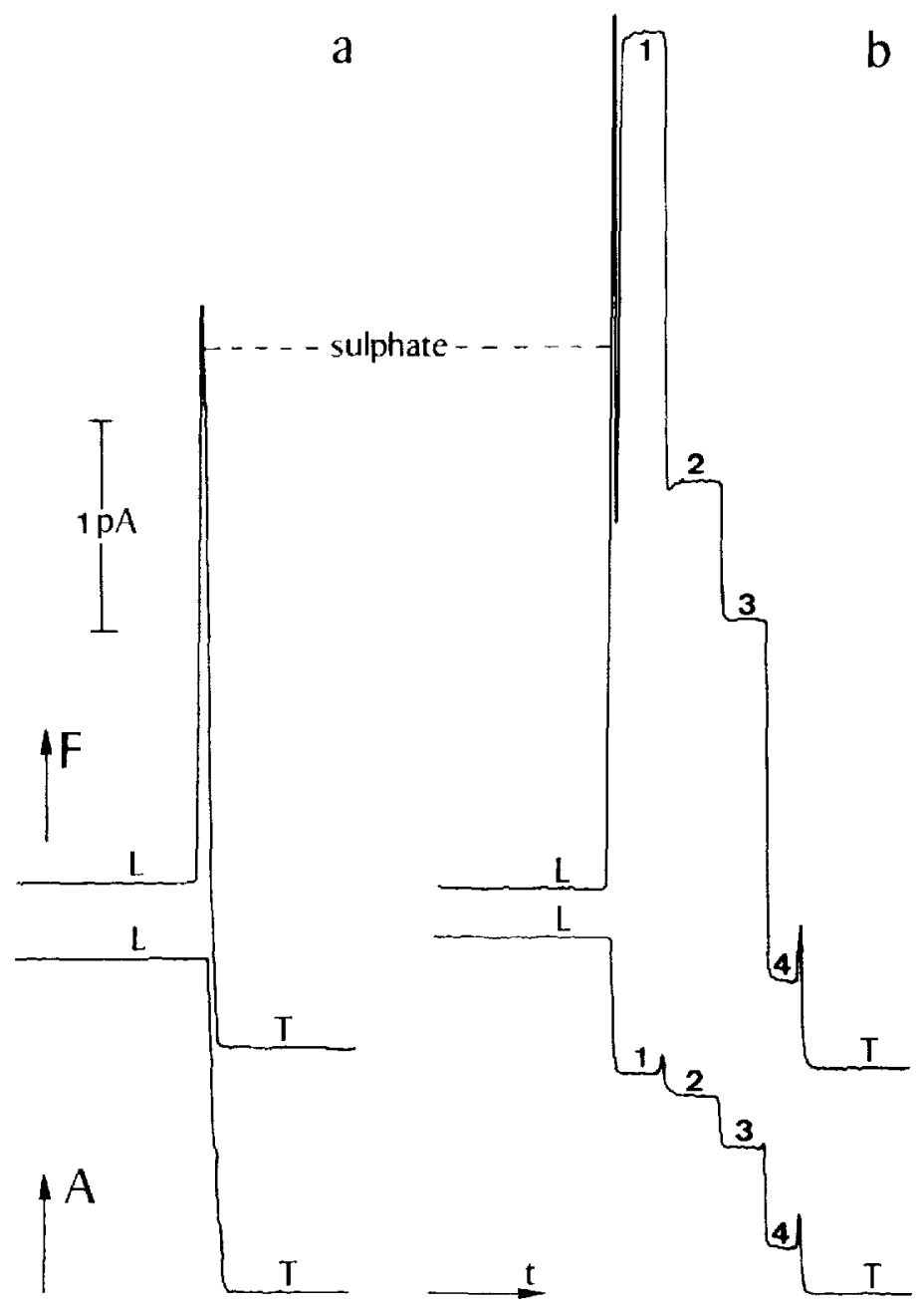

Fig. 10. Fluorescence quenching as a detection method in isotachophoresis. The operational system uses a fluorescent counter ion (Table II). A leading-terminator zone transition (a) shows a decrease in fluorescence (F) and absorption (A). From both signals fluorescence quenching was calculated (see text). In (b) the detection of 1 nmole each of phosphoric (1), citric (2), malic (3) and lactic acids (4) is shown. Additional impurities are also detected. 
by isotachophoresis with UV detection. Although ANS is widely used in spectrofluorimetric determinations of proteins ${ }^{4}$, its use in separation techniques such as isotachophoresis may be limited to binding studies, because of the nature of the interaction. The stability of the protein-dye complex in a high electric field is doubtful especially with weaker binding sites ${ }^{6}$ where a physical interaction rather than the product of a chemical reaction is likely to prevail. A chemical reaction does take place when reacting primary amino groups with fluorescamine ${ }^{7}$. The use of fluorescamine for the fluorimetric determination of proteins in SDS-polyacrylamide gel electrophoresis ${ }^{8}$ was reported. The reagent is also suitable for primary amino acids, which can then be analysed as anions at neutral $\mathrm{pH}$, an additional advantage. This is because the reaction involves a replacement of the positively charged amino group with a negatively charged fluorophor. Fig. 9 illustrates the use of fluorescamine in amino acid analysis with isotachophoresis. Fig. $9 \mathrm{a}$ is a blank run, in which the reagent is converted in the high-pH buffer to a nonfuorescent, albeit UV-absorbing, product that migrates as an anion. Fig. $9 \mathrm{~b}$ shows the analysis of $\alpha$-alanine derivatized with excess of fluorescamine. The specificity of detection with fluorescence is clearly demonstrated.

In spectrofluorimetry it is sometimes possible to quantitate a non-fluorescent compound by measuring its quenching of the fluorescence emission of another compound, added to the sample in a defined amount and environment ${ }^{4}$. As mostly qualitative information is obtained from the signal amplitude in isotachophoresis, fluorescence quenching as a detection method for isotachophoretic zones will give information on the identity of the corresponding sample ion. The method is illustrated in Fig. 10. Ouinine was used as a fluorescent buffering counter ion at its $\mathrm{p} K$ value in an anionic operational system of $\mathrm{pH} 4.13$ (Table II). The leading-terminator zone transition (Fig. 10a) shows a stepwise decrease in both fluorescence emission and UV absorption at $360 \mathrm{~nm}$, the optimal wavelength of excitation for quinine in the leading electrolyte. A separation of phosphoric, citric, malic and lactic acids is shown in Fig. $10 \mathrm{~b}$.

TABLE III

$\mathrm{p} K_{1}$ VALUES AND FLUORESCENCE QUENCHING OF 34 ANIONS AS ANALYSED BY ISOTACHOPHORESIS IN A FLUORESCENT OPERATIONAL SYSTEM (TABLE II)

\begin{tabular}{|c|c|c|c|c|c|}
\hline Name & $p K_{1, i}$ & $Q_{r e l, i}$ & Name & $p K_{1, i}$ & $Q_{r e l, i}$ \\
\hline Chlorate & -2.7 & -0.72 & Salicylate & 3.08 & 0.37 \\
\hline Pcrchlorate & -2 & -0.70 & Monoiodoacetate & 3.12 & 0.06 \\
\hline Sulphamate & -2 & -0.59 & Formate & 3.75 & 0.56 \\
\hline Nitrate & -1.4 & -0.70 & Hippurate & 3.80 & 0.09 \\
\hline Trichloroacetate & 0.70 & -0.43 & Mandelate & 3.85 & 0.07 \\
\hline Pyrophosphate & 0.85 & -0.39 & Gluconate & 3.86 & 0.04 \\
\hline Butanesulphonate & $1 \star$ & -0.11 & B-Chloropropionate & 3.98 & 0.03 \\
\hline Hexanesulphonate & $1 \star$ & -0.15 & p-Chlorobenzoate & 3.98 & 0.12 \\
\hline Octanesulphonate & $1 \star$ & -0.17 & Ascorbate & 4.10 & 0.77 \\
\hline Sulphite & 1.81 & -0.18 & Benzoate & 4.19 & 0.18 \\
\hline Orthophosphate & 2.12 & -0.60 & Glutamate & 4.25 & 0.31 \\
\hline Pyruvate & 2.50 & -0.46 & Acetate & 4.75 & 0.09 \\
\hline$\alpha$-Ketoglutarate & 2.80 & -0.06 & Nicotinate & 4.76 & 0.69 \\
\hline Malonate & 2.83 & -0.41 & Butyrate & 4.81 & 0.14 \\
\hline Tartrate & 2.98 & -0.32 & Benzyl-dl-aspartate & 4.86 & 0.09 \\
\hline Fumarate & 3.03 & -0.28 & Propionate & 4.87 & 0.14 \\
\hline Citrate & 3.08 & -0.19 & Pivalate & 5.01 & 0.84 \\
\hline
\end{tabular}

* Estimated value. 
The absorption and the fluorescence of a zone can be due to the sample ion and the counter ion. For sample ions without absorption at the wavelength of excitation ( $360 \mathrm{~nm}$ in this instance), only the counter ion is considered. Both absorption and fluorescence depend on concentration and $\mathrm{pH}$ (or rather the degree of dissociation). For sample constituents with known absolute mobilities and $\mathrm{p} K$ values, fluorescence quenching can be calculated, provided that the relationship between fluorescence, concentration and $\mathrm{pH}$ is known. This requires pre-information not usually available. On the other hand, the $\mathrm{p} K$ value of an unidentified component can be estimated from its fluorescence quenching. Therefore, for identification purposes a phenomenological approach seems more attractive. The fluorescence intensity of zone $i\left(F_{i}\right)$, relative to that of the leading $\left(F_{\mathrm{L}}\right)$ and the terminator $\left(F_{\mathrm{T}}\right)$ zone, is now defined as

$$
F_{\mathrm{rel}, i}=\left(F_{i}-F_{\mathrm{T}}\right) /\left(F_{\mathrm{L}}-F_{\mathrm{T}}\right)
$$

and analogously for the relative transmission of zone $i$ :

$$
T_{\mathrm{rel}, i}=\left(T_{i}-T_{\mathrm{T}}\right) /\left(T_{\mathrm{L}}-T_{\mathrm{T}}\right)
$$

A high quenching always coincides with a low transmission and a low fluorescence. The relative quenching of a zone $i\left(Q_{\mathrm{rel}, i}\right)$ is now defined as

$$
Q_{\mathrm{rel}, i}=-\log \left(F_{\mathrm{rel}, i} T_{\mathrm{rel}, i}\right)
$$

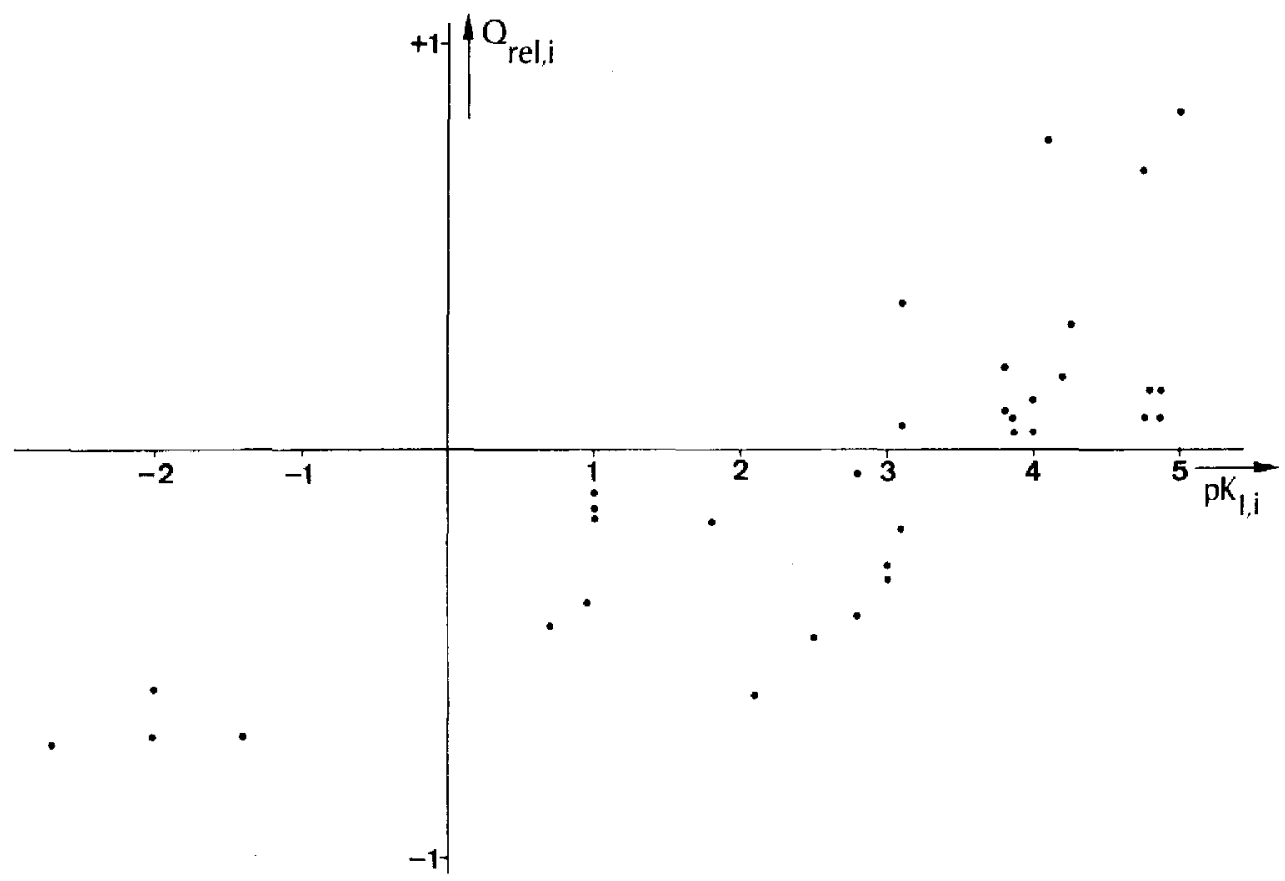

Fig. 11. Relalive quenching, $Q_{\text {rel }}$ of a number of organic and inorganic acids in a fluorescent anionic operational system (Table II) versus their $\mathrm{p} K_{1}$ values. Strong $\left(\mathrm{p} K_{1}<3\right)$ and weak $\left(\mathrm{p} K_{1}>3\right)$ acids can be distinguished. See text for further explanation. 
A number of organic and inorganic acids were analysed in the operational system mentioned and fluorescence quenching was calculated with eqn. 5. Care was taken to eliminate those acids showing UV absorption at $360 \mathrm{~nm}$. The results are shown in Table III and Fig. 11, where quenching is plotted versus the $\mathrm{p} K_{1}$ value of the corresponding acids. Keeping in mind that the leading electrolyte $\mathrm{pH}$ is 4.13 , acids with a $\mathrm{p} K_{1}$ higher than 3 can be considered weak. These ions evidently show positive quenching. Strong ions with a $\mathrm{p} K$ lower than 3 show negative quenching (Fig. 11). Fluorescence quenching can thus be used to distinguish between strong and weak unidentified components in a single run. The only pre-information needed is whether the components show absorption at the wavelength of excitation. This would require an additional run at the same $\mathrm{pH}$ but with a non-UV-absorbing counter ion ( $\gamma$-aminobutyric acid with $\mathrm{pK} 4.2$ in this instance).

\section{CONCLUSIONS}

The possibility of using fluorescence detection in isotachophoresis without an increase in the detector cell volume has been demonstrated. Although some non-linearity was observed only when using the spike method, the advantages are its greater sensitivity and selectivity. Ionic compounds can be detected by their native fluorescence, or a suitable reaction to yield a fluorescent ion is carried out. The $90^{\circ}$ configuration allows simultaneous UV absorption and fluorescence emission measurements. This makes it possible to apply computerized data reduction on the basis of the fluorescence/absorption ratio. An additional method of identification is fluorescence quenching to distinguish between strong and weak ions.

\section{REFERENCES}

1 F. M. Everaerts, J. L. Beckers and Th. P. E. M. Verheggen, Isotachophoresis, Theory, Instrumentation and Applications (Journal of Chromatography, Library, Volume 6), Elsevier, Amsterdam, 1976.

2 L. Arlinger, J. Chromatogr., 19 (1974) 785.

3 J. C. Reijenga, Th. P. E. M. Verheggen and F. M. Everaerts, J. Chromatogr., 267 (1983) 75.

4 G. G. Guilbault, Practical Fluorescence, Marcel Dekker, New York, 1973.

5 F. E. P. Mikkers, F. M. Everaerts and Th. P. E. M. Verheggen, J. Chromatogr, 169 (1979) 1.

6 C. J. Holloway and G. Bulge, J. Chromatogr., 234 (1982) 454.

7 M. Weigele, S. L. DeBernardo, J. P. Tengi and W. Leimgruber, J. Amer. Chem. Soc., 94 (1972) 5927

8 E. Alhanaty, M. Tauber-Finkelstein and S. Shaltiel, FEBS Lett., 125 (1981) 151. 